\title{
Predicting Risk Factors of Working Aged Hemorrhagic Stroke Patients in a Tertiary Volume 3(1): 1-7 (C)Author(s) 2018 Teaching Hospital in Chiang Mai \\ http://digitalscholarship.unlv.edu/apin/
}

\author{
Suphannee Triamvisit ${ }^{\mathrm{a}}$, Wilaiwan Chongruksut ${ }^{\mathrm{b}}$, Wanarak Watcharasaksilp ${ }^{\mathrm{b}}$, and Rujee \\ Rattanasathien $^{\mathrm{a}}$
}

\begin{abstract}
Stroke is the third leading cause of morbidity and mortality in Thailand accounting for a significant and increasing share of hospital costs. The purpose of this project is to study the epidemiology of the prevalence and its predicting factors of working aged hemorrhagic stroke (HS) patients admitted at a tertiary teaching hospital in Chiang Mai, Thailand.

We conducted a five-year retrospective descriptive study. The subjects in this study were patients diagnosed with HS, between 15-59 years of age, and admitted to a tertiary teaching hospital in Chiang Mai, Thailand from January 2009 to December 2013. A total of 404 working aged adults who had HS were admitted to the hospital during this review period; $60.9 \%$ males and $39.1 \%$ females. Nearly $70 \%$ of patients were between $46-59$ years of age $(M=47.5, S D=9.8)$. Of the patients admitted to the hospital, $76.7 \%$ were transferred there from other hospitals. Intracerebral hemorrhage was present in $59.7 \%$ of patients. Severe HS occurred in $35.9 \%$ of the patients with a Glasgow Coma Score from 3-8. Approximately $69 \%$ of the working aged HS patients required surgery. The top five identified risk factors for HS were hypertension (83.4\%), hyperlipidemia (38.9\%), alcohol consumption (21.5\%), smoking $(15.3 \%)$, and drug non-adherence $(14.9 \%)$.

We found significantly associated risk factors in working-aged HS by multivariate analysis among male gender $(p<.001)$, drug non-adherence $(p=.047)$, and hypertension $(p=.048)$. Raising awareness to reduce risk behavior and health promotion in the community are the keynotes for health care providers in working-aged HS prevention.
\end{abstract}

Keywords: predicting risk factors, hemorrhagic stroke, working aged

Hemorrhagic stroke (HS) is caused by the rupture of weakened arteries in the brain or surrounding the brain. The blood accumulates and compresses the surrounding brain tissue causing the brain tissue in that area to weaken and die (American Heart Association \& American Stroke Association, 2017). HS is life-threatening and often requires an operation, most frequently a craniotomy to remove the hematoma or inserted external ventriculostomy drainage to reduce the increased intracranial pressure in the brain. There are two types of HSs: an intracerebral hemorrhage (ICH) and a subarachnoid hemorrhage. Together they comprise between $22-30 \%$ of all strokes in East Asia (Burke \& Venketasubramanian, 2006; Zhang et al., 2011). HS is often fatal or can cause permanent neurologic disability. The HS mortality rate in the United States is between 40 and 50\% (Woo et al., 2004). In Korea, the fatality rate is $40 \%$ at 1 month and $54 \%$ at 1 year period. Between 12-
$39 \%$ of survivors can achieve long-term functional independence (An, Kim, \& Yoon, 2017).

The prevalence of stroke in Thailand is estimated to be $1.88 \%$ of the population 45 years and older (Suwanwela, 2014). In Thailand among stroke sufferers of all kinds, $59.6 \%$ are male and $42.8 \%$ are people between 15-59 years of age (Areechokchai, Vijitsoonthornkul, Pongpan, \& Maeakhian, 2017). The population of Thailand may be divided into three major age groups: youth (aged under 15), working age (aged 15-59), and elderly (aged 60 and older).

\footnotetext{
${ }^{a}$ Chiang Mai University Hospital, Chiang Mai, Thailand

${ }^{b}$ Department of Surgery, Chiang Mai University, Chiang Mai,

Thailand

Corresponding Author:

Suphannee Triamvisit, RN, APN

Neurosurgical Critical Care Unit, Nursing Division, Chiang Mai

University Hospital, Chiang Mai, Thailand.

Email:nong.7081@gmail.com
} 
Table 1. Characteristic of Working Aged HS Patients $(\mathrm{N}=404)$

\begin{tabular}{lc}
\hline Characteristic of Working Aged HS Patients & $n(\%)$ \\
\hline Gender & \\
Male & $246(60.9)$ \\
$\quad \leq 45$ & $125(30.9)$ \\
$>45$ & $279(69.1)$ \\
$M(S D)$ & $47.5(9.8)$ \\
Accessibility & $310(76.7)$ \\
Transferred from other hospitals & $94(23.3)$ \\
Admitted directly & $163(40.3)$ \\
Diagnosis & $241(59.7)$ \\
SAH & \\
ICH & $145(35.9)$ \\
GCS at Admission & $259(64.1)$ \\
GCS $\leq 8$ & $10.4(3.9)$ \\
GCS $>$ 8 & \\
$M(S D)$ & $124(30.7)$ \\
Operation & $280(69.3)$ \\
Non-Operation & $206(51.0)$ \\
Operation (subgroups) & $84(20.8)$ \\
Craniotomy & $24(5.9)$ \\
EVD & $11(2.7)$ \\
V-P shunt & $9(2.2)$ \\
Re-operation & $69(17.1)$ \\
\hline
\end{tabular}

Note. EVD = external ventriculostomy drainage; GCS = Glasgow Coma Score; $\mathrm{HS}=$ hemorrhagic stroke; $\mathrm{ICH}=$ intracerebral hemorrhage; $\mathrm{SAH}=$ subarachnoid hemorrhage.

The percentage of Thai youth and working aged population will continue to decline from the year 2010 to 2040, while that of the elderly will increase continuously from $13.2 \%$ in 2010 to $32.1 \%$ in 2040 (Foundation for Older Persons' Development, 2015). The incidence of stroke in the Thai working aged demographic is a major public health problem and has a negative impact on the economy. It can also be a burden on the families as victims can be left disabled and require ongoing care and support. This problem is compounded as the Thai society is becoming an increasingly elderly society (Foundation for Older Persons' Development, 2015).

Previous studies found that HS is related to hypertension, alcohol consumption, anticoagulant use, diabetes mellitus, serum cholesterol levels more than $200 \mathrm{mg} / \mathrm{dl}$, body mass index greater than 25 , genetics, and hyperuricemia. Another emerging risk factor is poor kidney function (Centers for Disease Control and Prevention, 2017; Daniel, \& Bereczki, 2004; Feigin, 2005; Ikram, Wieberdink, \& Koudstaal, 2012; Wang, Dong, Qi, Huang, \& Hou, 2013). The severity of disability, likelihood of death, lengths of hospital stay, and cost of treatment of HS patients are higher than ischemic stroke (Gioldasis, 2008; Reed, Blough, Meyer, \& Jarvik, 2001; Yoneda et al., 2005). ICH patients had a higher baseline stroke severity, resulting in longer hospitalization, higher disability rates at discharge, higher mortality rates, and higher medical costs (Chiu et al., 2010; Christensen, 2009; Gioldasis, 2008; Reed et al., 2001; Yoneda et al., 2005). Previous studies have looked at risk factors associated with HS in many countries, including Thailand, but not specific to Northern Thailand and not specific to the working aged population. Research into the specific risk factors associated with HS in this demographic could promote primary prevention and therefore, reduce the burden of stroke. The purpose of this study was to identify the risk factors associated with working aged HS patients who underwent treatment in a tertiary teaching hospital in Chiang Mai, a tertiary care center in Northern Thailand.

\section{Method}

\section{Study Design}

The Ethics Committee of the Faculty of Medicine, Chiang Mai University, Chiang Mai, Thailand, approved this study (NUR-2557-2100). Patients included in this study ranged from 15-59 years and were given ICD-9-CM Diagnosis Code I60 or I61. Code I60 indicates non-traumatic subarachnoid hemorrhage, and Code I61 indicates non-traumatic intrac- 
Table 2. Source of Admission by GCS

\begin{tabular}{|c|c|c|c|}
\hline $\begin{array}{l}\text { GCS Ad- } \\
\text { mission }\end{array}$ & $\begin{array}{c}\text { Transferred From } \\
\text { Other Hospitals } \\
n(\%)\end{array}$ & $\begin{array}{l}\text { Admitted } \\
\text { Directly } \\
n(\%)\end{array}$ & $p$-value \\
\hline $\begin{array}{l}3-8 \\
9-15\end{array}$ & $\begin{array}{l}120(38.7) \\
190(61.3)\end{array}$ & $\begin{array}{l}25(26.6) \\
69(73.4)\end{array}$ & $.037 *$ \\
\hline
\end{tabular}

Note. GCS = Glasgow Coma Score; $* p<.05$.

erebral hemorrhage. We gathered data on the patients from the hospital's electronic medical records; we performed a secondary analysis on this data. The patients were diagnosed with HS and admitted to the Neurosurgical Intensive Care Unit, the Neurosurgical Critical Care Unit, and the Acute Stroke Unit during the period from January 2009 to December 2013.

The general demographic information pertained to age and sex while the medical data consisted of the Glasgow Coma Score (GCS) at admission, subgroups of HS (ICH and subarachnoid hemorrhage), surgical treatment, and the risk factors associated with HS (i.e., hypertension, hyperlipidemia, regular alcohol consumption, drug non-adherence with anti-hypertensive medications, smoking, diabetes mellitus, prior stroke, diagnosed underlying neurological problem, chronic kidney disease, and coagulopathy). The GCS is a neurological scale used to assess the level of consciousness of the patients on admission. The initial score correlates with the severity of brain injury and prognosis. The GCS provides a score in the range 3 (worst prognosis) to 15 (best prognosis). Patients with scores equal to or less than 8 are usually comatose and will have severe disability, scores of 9-13 indicate the likelihood of moderate disability, and 14-15 indicate a good chance for a full recovery (Biau Organization, n.d.; Traumaticbraininjury.com, n.d.).

\section{Statistical Analysis}

We used the STATA 10 program to analyze the demographic data using descriptive statistics. Risk factors and comorbidity were analyzed using frequencies and percentages. Logistic multiple regression was used to analyze associated risk factors in working-aged HS patients. Other covariates such as age, sex, hypertension, hyperlipidemia, alcohol drinking, drug non-adherence, smoking, diabetes mellitus, prior stroke, neurological problem, kidney problem, and anticoagulant drug use were controlled by using a multivariable logistic analysis. The unavailable logistic regression was used to identify the possible independent risk factors for stroke. We included the clinically significant variables and all variables that had a $p$-value less than .01 in the multivariable analysis model. Multivariable logistic regression analysis and step-backward method were used to identify the independent risk factors for stroke. We considered a $p$-value less than .05 statistically significant.

\section{Results}

Our sample size was calculated based on a previous study which found that $45.9 \%$ of strokes among Thais were hemorrhagic strokes (Bandasak, Narksawat, Tangkanakul, Chinvarun, \& Siri, 2011). To calculate sample size in this study, the formula $n$ $=\mathrm{Z}^{2} \mathrm{P}(1-\mathrm{P}) / \mathrm{d}^{2}$ was used and provided a precision of 5\% (Pourhoseingholi, Vahedi \& Rahimzadeh, 2013). Using this formula, the recommended sample size was 382 cases. During the study period, we identified 647 hemorrhagic stroke patients. However, 404 met our inclusion criteria of being aged 15-59 years, which comprised our study sample. Table 1 shows the characteristics of the patients. The majority were male $(60.9 \%)$, and the mean age was 47.5 years $(S D$ =9.8). At the time of admission, 145 HS patients had suffered a severe stroke and had a GCS between 3 and 8. Two hundred and eighty of the HS patients required surgery while the remainder only needed supportive treatment. The three major surgeries performed were craniotomy, external ventriculostomy drainage, and craniectomy. Patients transferred from secondary hospitals $(n=120)$ had a GCS between 3 and 8 compared with 25 patients who admitted directly to the hospital in this study (Table 2).

Five principal risk factors were identified. Table 3 describes the risk factors associated with the HS patients. Univariate analysis indicated the significant risk factors were being male $(p<.001)$ and drug non-adherence of antihypertension $(p=.042)$. A multivariate analysis confirmed the same two risk factors, male gender $(p<.001, O R=2.43,95 \% \mathrm{CI}$ [1.60- 3.69] and drug non-adherence $(p=.047, O R=$ $1.88,95 \%$ CI $[1.01-3.50])$ were significant with the addition of hypertension $(p=.048, O R=1.81,95 \%$ CI [1.01-3.26]; Table 4).

\section{Discussion}

The present study indicated that males accounted for more than half of our HS patients. This was similar to others studies that found a higher ICH incidence in males than in females in Greece, Southern Norway, Australia, Japan, and East China (Gokhale, Caplan, \& James, 2015; Zhang et al., 2011).

The mean age of patients in our study was 47.5 years $(S D=9.8)$ years. We found that $69.1 \%$ of our stoke victims were aged 46-59 years, while $30.9 \%$ were aged $15-45$ years. These results are similar to a study at a similar hospital (i.e., a tertiary hospital in a developing country, Bangladesh; Hussain, Mohammad, et al., 2015). In that study, $67.1 \%$ of the patients were over 45 years of age, and $33.9 \%$ were between 15-45 years of age. We speculate that, alt- 
Asian/Pacific Island Nursing Journal, Vol. 3, Iss. 1 [2018], Art. 1

Table 3. Risk Factors in Working Aged HS Patients by Univariate Analysis

\begin{tabular}{|c|c|c|c|c|}
\hline Risk factor & $n(\%)$ & $\begin{array}{l}\text { Crude } \\
O R \\
\end{array}$ & $95 \% C I$ & $p$-value \\
\hline Male & $246(60.9)$ & 2.508 & $1.661-3.787$ & $<.001 * * *$ \\
\hline Age $>45$ & $279(69.1)$ & 1.435 & $0.936-2.198$ & 0.098 \\
\hline Hypertension & $337(83.4)$ & 0.597 & $0.338-1.053$ & 0.075 \\
\hline Hyperlipidemia (>200 mg/dl) & $157(38.9)$ & 0.880 & $0.575-1.347$ & 0.558 \\
\hline Alcohol drinker & $87(21.5)$ & 1.138 & $0.697-1.852$ & 0.604 \\
\hline Smoker & $62(15.3)$ & 1.175 & $0.672-2.054$ & 0.571 \\
\hline Drug non-adherence & $60(14.9)$ & 1.865 & $1.023-3.401$ & $0.042 *$ \\
\hline Diabetes mellitus & $49(12.1)$ & 1.078 & $0.584-1.988$ & 0.877 \\
\hline Old CVA & $26(6.4)$ & 1.564 & $0.663-3.687$ & 0.307 \\
\hline Neurological problem & $18(4.5)$ & 0.839 & $0.324-2.172$ & 0.717 \\
\hline Heart problem & $16(4.0)$ & 0.900 & $0.199-4.076$ & 0.891 \\
\hline Kidney problem & $15(3.7)$ & 0.765 & $0.272-2.153$ & 0.604 \\
\hline Coagulopathy & $12(3.0)$ & 3.485 & $0.754-16.116$ & 0.110 \\
\hline
\end{tabular}

Note. $\mathrm{CVA}=$ cerebrovascular accident; $\mathrm{HS}=$ hemorrhagic stroke; $* * * p<.001 ; * p<.05$.

hough both Bangladesh and Thailand are considered to be developing countries, Thailand is an upper income developing country with differences in lifestyle, access to health care, and other socio-economic factors that impact these results. Although only a small proportion of working aged people experience a stroke, the results are nonetheless significant as these working aged survivors may become dependent, unable to participate in the workforce, and require assistance for the rest of their lives. The effect of this is a significant loss of economic productivity and a prolonged financial burden, which has a negative impact on their families, communities, the health care system, and the nation as a whole.

The mean GCS at admission was 10.4 (SD = 3.9), which indicated a moderate HS. There were 145 (35.9\%) patients with a GCS ranging from 3-8, showing severe disability (Biau Organization, n.d.; Traumaticbraininjury.com, n.d.). There was a large number of patients $(n=310)$ who were transferred from other hospitals. The physicians from outlying regions tend to transfer their patients to the hospital in this study who require the most intense treatment. At admission, $26.6 \%$ of patients admitted directly to the hospital in this study had a GCS ranging from 3-8, while $38.7 \%$ of patients transferred from outlying hospitals had a GCS in the same range $(p=<.037)$.

$\mathrm{HS}$ is a clinical emergency requiring urgent surgical and medical intervention. Recent advances in the organization of acute stroke care, and improved understanding of the evolving pathophysiology together with advances in acute pharmacological therapy, including neuroprotective approaches, are changing the way that acute stroke is managed around the world (Davis, Lees, \& Donnan, 2006). During the period under study, the hospital had the primary responsibility of treating patients with severe or complicated medical needs who required the most modern medical technology and interventions. The hospi- tal also had the responsibility to act as a mentor and to promote best practices and integrate care for patients at all stages of treatment. After the period of study, the National Health Ministry promoted the establishment of stroke units in all secondary and tertiary hospitals in Thailand. Some additional hospitals in Northern Thailand have already established stroke units and now have the potential to perform surgery and treat stroke patients with thrombolysis. We anticipate that this development will reduce the number of stroke patients who will be transferred to the hospital under study. The majority $(69.3 \%)$ of HS patients in this study required surgery. Some patients required more than one surgical procedure. The top three surgeries were craniotomy, external ventriculostomy drainage, and craniectomy. More than half $(51.0 \%)$ of the HS patients had craniotomies to remove a hematoma in the brain to decompress the brain tissue. Eighty-four $(20.8 \%)$ patients had external ventriculostomy drainage to reduce hydrocephalus, which may occur after HS because blood components occlude the cerebrospinal fluid drainage pathway. Twenty-four $(5.9 \%)$ craniectomies were performed in order to reduce secondary injuries from brain edema (Abdeen, Aboul-Henein, Orz, \& ElMetainy, n.d.; Bhattathiri, Gregson, Prasad, \& Mendelow, 2006; Bu et al., 2016; Chen, Luo, Reis, Manaenko, \& Zhang, 2017).

The significant predicting risk factors for working-aged HS patients were male, drug nonadherence for antihypertensive drugs, and hypertension. A study done in China suggested that males were at greater risk for HS because they had lifestyle differences, such as cigarette smoking and alcohol drinking. Also, there is no vascular protection of endogenous estrogen in males and it may contribute to the risk of stroke in men (Zhang et al., 2011). Hypertension is a main risk factor for HS, specifically untreated hypertension (Woo et al., 2004). Our study is 
Table 4. Risk Factor in Working Aged HS Patients by Multivariate Analysis

\begin{tabular}{lccc}
\hline Risk factor & Adjusted $O R$ & $95 \% C I$ & $p$-value \\
\hline Male & 2.43 & $1.60-3.69$ & $<.001^{* * *}$ \\
$\begin{array}{l}\text { Drug non- } \\
\text { adherence }\end{array}$ & 1.88 & $1.01-3.50$ & $0.047^{*}$ \\
Hypertension & 1.81 & $1.01-3.26$ & $0.048^{*}$ \\
\hline
\end{tabular}

Note. Adjusted by sex, age $>45$, drug non adherence and hypertension; HS = hemorrhagic stroke; $* * * p<.001 ; * p<$ .05 .

similar to a systematic review of risk factors for intracerebral hemorrhage in the general population that found male sex and hypertension (Ariesen, Claus, Rinkel, \& Algra, 2003). Our results are consistent with the previous study showing that medication nonadherence was associated with insufficient blood pressure control and increased risk of incident stroke (Cummings et al., 2013; Hussain, Azad, et al., 2015).

Non-medication adherence was associated with working-aged victims who were young, working, and presented with overweight or obesity as found in a study in Brazil (Demoner, de Paula Ramos, \& Pereira, 2012). The reasons for drug nonadherence may be due to normalization of blood pressure, side effects of the medications, forgetting to use the medication, cost of medication, fear of mixing alcohol and medication, ignoring the need for continuing the treatment, use of an alternative treatment, fear of intoxication, fear of hypotension, and fear of mixing the medication with other drugs (Andrade, Vilas-Boas, Chagas, \& Andrade, 2002).

A multinational study found an association between low age, low self-efficacy, respondents' perception of their illness, and cost-related barriers with medication non-adherence (Morrison et al., 2015). Individuals with hypertension who fail to take their prescribed antihypertensive medication experience a substantially increased risk of fatal stroke (Herttua, Martikainen, Batty, \& Kivimäki, 2016). A retrospective cohort study in Korea about the effect of adherence to antihypertensive medications found a significant association between poor adherence and non-adherence to medication with a higher risk of stroke (Lee, Jang, \& Park, 2017).

A systematic review of 97 articles published between 1979 and 2009, of the impact of the intervention on medication adherence and blood pressure control in patients with hypertension, found that improving knowledge of medications had potential clinical value in improving adherence with antihypertensive therapy (Gwadry-Sridhar, 2013). In a study in Spain, a team of pharmacists provided specific education on medication adherence and hypertension to some patients who were taking anti-hypertensives. There was a significant improvement in antihypertensive medication adherence compared to a control group who did not receive this education $(p<.05$; Fikri-Benbrahim, Faus, Martínez-Martínez, \& Sabater-Hernández, 2013). Another study found that adherence to medications was positively correlated to increasing age $(p<.001)$, the presence of hypertension $(p<.05)$, and a more positive attitude toward health $(p<.001$; Alefishat, Abu Farha, \& Al-Debei, 2017).

We suggest that there is a particular need for primary prevention and a need to address the significant associated risk factors. There is also a need to provide more information to working aged stroke victims to enhance their knowledge of hypertension and HS. We postulate that such measures can lead to a more positive attitude toward their health and a greater sense of self-efficacy, which in turn may affect adherence rates in patients (Morrison et al., 2015). Increased medication adherence should lead to more normal blood pressure and fewer negative outcomes. These educational programs could be incorporated into the current efforts to manage the patient's hypertension.

A prime responsibility of the nursing professional is to empower patients to look after their own health needs. For patients with hypertension, this involves helping patients to understand their disease and to realize the importance of medication adherence to antihypertensive drugs so that their blood pressure may be brought under control to reduce the risk of HS. Case management by nurses in the community is one way of addressing this issue. Case managers can offer outreach services to working aged adults who are known to have hypertension and proactively encourage these adults to learn about their disease and take measures to reduce the risk factors leading to HS. Knowledge sharing among medical professionals in the community and associated hospitals is an important aspect of identifying and contacting this group and encouraging their involvement in various preventive measures, especially medication adherence.

There is a need for further research to establish which approaches will be most effective in increasing drug compliance in the working aged group. Future study should have as its goal the development of an overall and integrated model of care and outreach to reduce the various factors that increase the risk of HS.

\section{Limitations}

This retrospective study was limited to using medical records already on file. Patient histories were sometimes sketchy as the patients were often in medical distress and could not provide information, which then had to be obtained from their relatives. Some of the transferring hospitals either did not have complete medical files on the transferred patients or 
that information was not supplied to the receiving hospital.

\section{Acknowledgments}

We would like to express our appreciation to Mr. William Leslie for his assistance as an English language consultant. We would like to thank the nurses of the Neurosurgical Critical Care Unit and Acute Stroke Unit, Chiang Mai University Hospital, Chiang Mai, Thailand for their assistances in data collection.

\section{Declaration of Conflicting Interests}

The author(s) declared no potential conflicts of interest concerning the research, authorship, or publication of this article.

\section{Funding}

This study was in financially supported by the Faculty of Medicine, Chiang Mai University, Chiang Mai, Thailand.

\section{References}

Abdeen, K, Aboul-Henein, H., Orz, Y., \& El-Metainy, S. A. (n. d.). Decompression craniectomy: Rationale, indications and outcome. www.surgical neurology.org/conf7/files/decompressive craniectomy.pdf

Alefishat, E. A., Abu Farha, R. K., \& Al-Debei, M. M. (2017). Self-reported adherence among individuals at high risk of metabolic syndrome: Effect of knowledge and attitude. Medical Principles and Practice, 26, 157-163. https://doi.org/10.1159/ 000453037

American Heart Association \& American Stroke Association. (2017). Hemorrhagic strokes (bleeds). Retrieved from http://www.strokeassociation.org/ STROKEORG/AboutStroke/TypesofStroke/Hem orrhagicBleeds/Hemorrhagic-Strokes-Bleeds UCM 310940_Article.jsp\#

An, S. J., Kim, T. J., \& Yoon, B. W. (2017). Epidemiology, risk factors, and clinical features of intracerebral hemorrhage: An update. Journal of Stroke, 19, 310. https://doi.org/10.5853/jos.2016.00864

Andrade, J. P., Vilas-Boas, F., Chagas, H., \& Andrade, M. (2002). Epidemiological aspects of adherence to the treatment of hypertension. Arquivos Brasileiros de Cardiologia, 79, 380-384. https://doi.org/ 10.1590/s0066-782x2002001300005

Areechokchai, D., Vijitsoonthornkul, K., Pongpan, S., \& Maeakhian, S. (2017). Population attributable fraction of stroke risk factors in Thailand: Utilization of non-communicable disease surveillance systems [Abstract]. Outbreak, Surveillance \& Investigation Reports, 10(1), 1-6.
Ariesen, M. J., Claus, S. P., Rinkel, G. J., \& Algra, A. (2003). Risk factors for intracerebral hemorrhage in the general population: A systematic review. Stroke, 34, 2060-2065. https://doi.org/10.1161/ 01.str.0000080678.09344.8d

Bandasak, R., Narksawat, K., Tangkanakul, C., Chinvarun, Y., \& Siri, S. (2011). Association between hypertension and stroke among Thai adults in Bangkok, Thailand. Southeast Asian Journal of Tropical Medicine and Public Health, 42 1241-1248.

Bhattathiri, P. S., Gregson, B., Prasad, K. S. M., \& Mendelow, A. D. (2006). Intraventricular hemorrhage and hydrocephalus after spontaneous intracerebral hemorrhage: Results from the STICH trail. Acta Neurochirurgica Supplementum, 65-68. https://doi.org/10.1007/3-211-30714-1_16

Biau Organization. (n.d.). Glasgow coma scale. Retrieved from https://biau.org/about-brain- injuries/whatto-expect/coma-patient-score-glasgow/

Bu, Y., Chen, M., Gao, T., Wang, X., Li, X., \& Gao, F. (2016). Mechanisms of hydrocephalus after intraventricular haemorrhage in adults. Stroke and Vascular Neurology, 1, 23-27. https://doi.org/ 10.1136/svn-2015-000003

Burke, T. A., \& Venketasubramanian, R. N. (2006). The epidemiology of stroke in the East Asian region: A literature-based review. International Journal Stroke, 1, 208-215. https://doi.org/10.1111/j. 1747-4949.2006.00060.x

Centers for Disease Control and Prevention. (2017). Overweight \& obesity: Adult overweight and obesity. Retrieved from http://www.cdc.gov/obesity/adult/ index.html

Chen, S., Luo, J., Reis, C., Manaenko, A., \& Zhang, J. (2017). Hydrocephalus after subarachnoid hemorrhage: Pathophysiology, diagnosis, and treatment. BioMed Research International, Article ID 8584753, 1-8. https://doi.org/10.1155/2017/858 4753

Chiu, D., Peterson, L., Elkind, M. S., Rosand, J., Gerber, L. M., \& Silverstein, M. D. (2010). Comparison of outcomes after intracerebral hemorrhage and ischemic stroke. Journal of Stroke \& Cerebrovascular Diseases, 19, 225-229. https://doi.org/ 10.1016/j.jstrokecerebrovasdis.2009.06.002

Christensen, M. C., Previgliano, I., Capparelli, F. J., Lerman, D., Lee, W. C., \& Wainsztein, N. (2009). Acute treatment costs of intracerebral hemorrhage and ischemic stroke in Argentina. Acta Neurologica Scandinavica, 119, 246-253. https:// doi.org/10.1111/j.1600-0404.2008.01094.X

Cummings, D. M., Letter, A. J., Howard, G., Howard, V. J., Safford, M. M., Prince, V., \& Muntner, P. (2013). Medication adherence and stroke/TIA risk in treated hypertensives: Results from the REGARDS study. Journal of American Society of Hypertension, 7, 363-369. https://doi.org/ $\underline{10.1016 / j . j a s h .2013 .05 .002}$

Daniel, S., \& Bereczki, D. (2004). Alcohol as a risk factor for hemorrhagic stroke. Ideggyogy Szemle, 57, 247-256.

Davis, S., Lees, K., \& Donnan, G. (2006). Treating the acute stroke patient as an emergency: Current practices and future opportunities. International 
Journal of Clinical Practice, 60, 399-407. https:// doi.org/10.1111/j.1368-5031.2006.00873.x

Demoner, M. S., de Paula Ramos, E. R., \& Pereira, E. R. (2012). Factors associated with adherence to antihypertensive treatment in a primary care unit. Acta Paulista de Enfermagem, 25(Special Issue 1), 27-34. https://doi.org/10.1590/s0103-210020 12000800005

Feigin, V. L, Rinkel, G. J. E., Lawes, C. M. M., Algra, A., Bennett, D. A., van Gijn, J., \& Anderson, C. S. (2005). Risk factors for subarachnoid hemorrhage: An update systematic review of epidemiological studies. Stroke, 36, 2773-2780. https:// doi.org/10.1161/01.str.0000190838.02954.e8

Fikri-Benbrahim, M., Faus, M. J., Martínez-Martínez, F., \& Sabater-Hernández, D. (2013). Impact of a community pharmacists' hypertension-care service on medication adherence. The AFenPA study. Research in Social and Administrative Pharmacy, 9, 797-805. https://doi.org/10.1016/j.sapharm.2012. $\underline{12.006}$

Foundation for Older Persons' Development. (2015). Situation of the Thai elderly (population situations). Retrieved from http://fopdev.or.th/situation-ofthe-thai-elderly-population-situations/

Gioldasis, G., Talelli, P., Chroni, E., Daouli, J., Papapetropoulos, T., \& Ellul, J., (2008). In- hospital direct cost of acute ischemic and hemorrhagic stroke in Greece. Acta Neurologica Scandinavica, 118, 268-274. https://doi.org/10.1111/j.16000404.2008.01014.x

Gokhale, S., Caplan, L. R., \& James, M. L. (2015). Sex differences in incidence, pathophysiology, and outcomes of primary intracerebral hemorrhage. Stroke, 46, 886-892. https://doi.org/10.1161/ strokeaha.114.007682

Gwadry-Sridhar, F. H., Manias, E. Lal, L., Salas, M., Hughes, D. A., Ratzki-Leewing, A., \& Grubisic, M. (2013). Impact of interventions on medication adherence and blood pressure control in patients with essential hypertension: A systematic review by the ISPOR Medication Adherence and Persistence Special Interest Group. Value in Health, 16, 863-871. https://doi.org/10.1016/i.jval.2013.03. $\underline{1631}$

Herttua, K., Martikainen, P., Batty, G. D., \& Kivimäki, M. (2016). Poor adherence to statin and antihypertensive therapies as risk factors for fatal stroke. Journal of the American College of Cardiology, 67, 1507-1515. https://doi.org/10.1016/j.jacc. $\underline{2016.01 .044}$

Hossain, M. Z., Azad, K. A. K., Hasan, P., Hussain, T., Rahman, K. M., Saleh, M.A.D., ... Karim. E. (2015). Discontinued anti-hypertensive medication: A case control study on the stroke patients. Journal of Dhaka Medical College, 22, 173-178. https://doi.org/10.3329/jdmc.v22i2.21530

Hussain, M. E, Mohammad, Q. D., Habib, M., Hoque, A., Alam, B., \& Yusuf, A. (2015). Aetiology of spontaneous intracerebral haemorrhage in young adults admitted at a tertiary care hospital in Dhaka. American Journal of Neuroscience, 6(2), 2025. https://doi.org/10.3844/amjnsp.2015.20.25

Ikram, M. A., Wieberdink, R. G., \& Koudstaal, P. J. (2012). International epidemiology of intracerebral hemorrhage. Current Atherosclerosis Reports, 14, 300-306.

Lee, H. J., Jang, S. I., \& Park, E. C. (2017). Effect of adherence to antihypertensive medication on stroke incidence in patients with hypertension: A population-based retrospective cohort study. British Medical Journal Open, 7(6), e014486. https:// doi.org/10.1136/bmjopen-2016-014486

Morrison, V. L., Holmes, E. A. F., Parveen, S., Plumpton, C. O., Clyne, W., Geest, S. D.,. Kardas, P. (2015). Predictors of self-reported adherence to antihypertensive medicines: A multinational, cross-sectional survey. Value in Health, 18, 206216. https://doi.org/10.1016/i.jval.2014.12.013

Pourhoseingholi, M. A., Vahedi, M., \& Rahimzadeh, M. (2013). Sample size calculation in medical studies. Gastroenterology and Hepatology from Bed to Bench, 6, 14-17.

Reed, S. D, Blough, D. K., Meyer, K., \& Jarvik, J. G. (2001). Inpatient costs, length of stay, and mortality for cerebrovascular events in community hospitals. Neurology, 57, 305314. https://doi. org/10.1212/wnl.57.2.305

Suwanwela, N. C. (2014). Stroke epidemiology in Thailand. Journal of Stroke, 11, 1-7. https://doi. org/10.5853/jos.2014.16.1.1

Traumatic Brain Injury.com. (n.d.). Glasgow coma scale. Retrieved from http://www.traumatic braininjury.com/symptoms-of-tbi/glasgowcoma-scale/

Wang, X., Dong, Y., Qi, X., Huang, C., \& Hou, L. (2013). Cholesterol levels and risk of hemorrhagic stroke: A systematic review and meta-analysis. Stroke, 44, 1833-1839. https: //doi.org/10.1161/strokeaha.113.001326

Woo, D., Haverbusch, M., Sekar, P., Kissela, B., Khoury, J., Schneider, A.,... Broderick, J. (2004). Effect of untreated hypertension on hemorrhagic stroke. Stroke, 35, 1703-1708. https://doi.org/10.1161/ 01.str.0000130855.70683.c8

Yoneda, Y., Okuda, S., Hamada, R., Toyota, A., Gotoh, J., Watanabe, M., ... Hasegawa, Y. (2005). Hospital cost of ischemic stroke and intracerebral hemorrhage in Japanese stroke centers. Health Policy, 73, 202-211. https:// doi.org/10.1016/j.healthpol.2004.11.016

Zhang, J., Wang, Y., Wang, G. N., Sun, H., Sun, T., Shi, J. Q.,... Zhang, J. S. (2011). Clinical factors in patients with ischemic versus hemorrhagic stroke in East China. World Journal of Emergency Medicine, 2, 18-23. https://doi.org/10.5847/wjem.j.1920-8642. $\underline{2011.01 .003}$ 